\title{
BMJ Open Return to work after knee replacement: a qualitative study of patient experiences
}

\author{
Michelle Bardgett, ${ }^{1}$ Joanne Lally, ${ }^{2}$ Ajay Malviya, ${ }^{3}$ David Deehan ${ }^{4}$
}

To cite: Bardgett M, Lally J, Malviya A, et al. Return to work after knee replacement: a qualitative study of patient experiences. BMJ Open 2016;6:e07912. doi:10.1136/bmjopen-2015007912

- Prepublication history for this paper is available online. To view these files please visit the journal online (http://dx.doi.org/10.1136/ bmjopen-2015-007912)

Received 10 February 2015 Revised 5 November 2015 Accepted 9 November 2015

\section{(1) CrossMark}

${ }^{1}$ Clinical Academic Unit, Newcastle upon Tyne NHS Foundation Trust, Newcastle upon Tyne, UK

${ }^{2}$ Institute of Health and Society, Newcastle University, Newcastle upon Tyne, UK

${ }^{3}$ Department of Orthopaedic Surgery, Northumbria Healthcare NHS Foundation Trust, Newcastle upon Tyne, UK

${ }^{4}$ Department of Orthopaedic Surgery, Newcastle upon Tyne NHS Foundation Trust, Newcastle upon Tyne, UK

Correspondence to Michelle Bardgett; Michelle.bardgett@nuth.nhs. uk

\section{ABSTRACT}

Objective: An increasing number of patients in the working population are undergoing total knee replacement (TKR) for end-stage osteoarthritis. The timing and success of return to work is becoming increasingly important for this group of patients with social and economic implications for patients, employers and society. There is limited understanding of the patient variables that determine the ability to return to work. Our objective was (from the patient's perspective) to gain an insight into the factors influencing return to work following knee replacement. Setting and participants: This qualitative study was undertaken in a secondary-care setting in a large teaching hospital in the north of England.

Semistructured interviews were carried out with 10 patients regarding their experiences of returning to work following TKR.

Outcomes: Interviews were transcribed and analysed using a qualitative thematic approach to identify the factors influencing return to work from the patient's perspective.

Results: Three themes were identified that influenced the process of return to work, from the patient's perspective. These were delays in surgical intervention, limited and often inconsistent advice from healthcare professionals regarding return to work, and finally the absence of rehabilitation to optimise patient's recovery and facilitate return to work.

Conclusions: There is currently no consistent process to optimise return to work for patients of working age after TKR. The impact of delayed surgical intervention, limited advice regarding return to work, and a lack of work-focused rehabilitation, all contribute to potential delays in successful return to work. There is a need to change the focus of healthcare provision for this cohort of patients, and provide a tailored healthcare intervention to optimise patient outcomes.

\section{INTRODUCTION}

The impact of knee osteoarthritis (OA) on quality of life, work productivity and employment in patients of working age is well documented with substantial indirect costs resulting from reduced work performance, absenteeism and job loss. ${ }^{1-3}$ Total knee replacement (TKR) is increasingly being judged as a highly successful procedure to

\section{Strengths and limitations of this study}

- Successful return to work is increasingly recognised as an important outcome for patients following joint replacement, with social and economic implications for patients, employers and society. The information regarding factors influencing the process of return to work from the patient's perspective is limited.

- Qualitative research methods were used to gain an understanding of patients' experiences following total knee replacement.

- This study was undertaken with a small sample at a single site, and the extent to which these findings relate to other regions and groups of patients is unknown.

- However, this work highlights the need to review the focus of healthcare provision for this cohort of patients and provide a tailored healthcare intervention to optimise patient outcomes and return to work.

reduce pain, improve function and quality of life in patients suffering from primaryOA. ${ }^{4}$ TKR had previously been considered an intervention for the older retired patient. More than 90000 knee replacement procedures were recorded in England and Wales in 2012, representing an increase of $7.3 \%$ compared with 2011. ${ }^{6}$ With the increasing overall numbers of patients undergoing surgery in conjunction with the rising retirement age, there is an absolute increase in such procedures being performed in patients under 65 years of age now looking to remain in employment. ${ }^{78}$ Early return to employment has recognised physical and mental health, social and economic benefits for patients and society. ${ }^{48}$ There is increasing awareness that successful return to work is a crucial marker of outcome for patients after TKR. ${ }^{10-13}$

Previous quantitative studies focusing on employment status, predictive factors and rates of return to work have identified age, employment before surgery, type of job and socioeconomic status as important determinants of successful return to work following joint replacement. ${ }^{12} \quad{ }^{14-17}$ While these 
quantitative studies provide crude measures of predictive factors and rates of return to work, such work takes no account of the patient experience and the mechanism by which these factors influence the process of return to work. ${ }^{17}$ There is paucity of information regarding factors influencing the process of return to work, from the patient's perspective. Qualitative research allows for a detailed assessment of patients' attitudes and understandings through their own accounts, and could therefore identify issues for patients not apparent to someone without their perspectives or experience. ${ }^{18}$

We performed semistructured interviews with 10 employed patients who had undergoneTKR. We focused on the preoperative and early postoperative phases of the patient's journey, with a view to identifying why certain factors may influence a patient's return to work, and potential deficiencies in the delivery of care directly pertinent to return to work.

\section{PATIENTS AND METHODS}

This qualitative study was performed at a large teaching hospital in the north of England. Interviews were carried out with 10 patients over a 4-month period between December 2013 and March 2014.

Participants were selected from a cohort of 50 TKR patients recruited into a population-based postal questionnaire study investigating barriers and facilitators to return to work after joint replacement carried out at the same institution. ${ }^{19}$ All patients were under the age of 60 years at the time of primary knee replacement surgery for OA. The aim of this study was to identify factors influencing return to work following knee replacement; therefore, patients were excluded from interview if they were unemployed in the 3 months prior to surgery. From the cohort of 50 patients, 37 patients were in employment preoperatively, and consented to be approached for interview. From these, purposive sampling was used to select patients with a range of characteristics known to influence rates of return to work such as age, gender and type of employment. Interviews were undertaken with 10 patients. Our aim was to gain a greater insight into the factors influencing return to work from the patient's perspective, and to identify key themes to inform future research in respect to optimising return-to-work outcomes.

Patients were asked to discuss the impact of their knee symptoms and surgery on work participation incorporating both preoperative and postoperative experiences during the interview. A semistructured topic guide was used to allow the patients to talk freely about their experiences and expand on any aspects they felt were relevant (figure 1). This resulted in a large variation in the length of interviews (30-100 min), but allowed patients to discuss important issues not previously considered by the researchers, and their impact on the patient's experience of return to work.
Introduction

1. Could you start by explaining to me what your job involves?

2. How did your arthritis affect youlyour work?

3. What has happened since your operation?

4. Was the experience after the operation what you were expecting?

5. What was the involvement of your employer?

6. Is there anything that has helped you/ or would have helped you to RTW more easily?

7. What influenced the decision to RTW at that time?

Close

Figure 1 Semistructured topic guide.

Interviews were undertaken by a trained research physiotherapist in the Musculoskeletal Outpatient Department of a large teaching hospital. Interviews were audio recorded and transcribed verbatim. All data was stored on a secure electronic data base, and paper copies filed in the Clinical Research Office, and complied with trust Caldicott Principles and the Data Protection Act (1988).

Written informed consent was obtained, and interview participants were allocated an identification number which was used throughout the study to ensure anonymity and maintain confidentiality.

The process used for analysis was based on thematic analysis as described by Braun and Clarke. ${ }^{20}$ Commonly used in healthcare research, thematic analysis is a qualitative descriptive method, which is independent of any one theory and epistemology. Thematic analysis was chosen as it specifies an analytical approach to coding and theme development, and has been successfully applied to qualitative questions such as lived experience and patients' understandings and perceptions. ${ }^{21-23}$ Using thematic analysis enabled the researchers to identify, analyse and report patterns (themes) across the data set, as well as working with a priori themes to provide a detailed account of the data and identify key issues in an area, where to date, there had been little research.

The researcher $(\mathrm{MB})$ repeatedly listened to interviews and reread the verbatim transcripts to ensure familiarity with the data set. Each transcript was systematically coded by hand to derive initial descriptive codes. This was an iterative process whereby new codes were identified to develop a consistent interpretation of the data set. A thematic approach enabled a deductive approach while also allowing themes to emerge from the data using inductive coding, ${ }^{24}$ which is seen as the most appropriate approach to use when little is known of the phenomena under investigation, as in the case with patients' experience of return to work. These initial 
descriptive codes were collated into more analytical themes and analysed at a latent level, to identify and refine the resulting themes and associations. ${ }^{20}$ Themes were data driven and determined by the research team as those that gave an important insight into the research question, capturing important elements of the patient's experiences and how these related to their return to work. As Braun and Clark ${ }^{20}$ argue that a theme's importance cannot be decided purely by prevalence, but comes down to researcher judgement on the relevance and importance of a theme to the research question. The researchers deemed a theme to be important if it added to the description and understanding of the factors patients identified as influencing their experience of return to work, ${ }^{24}$ and if there was meaningful data to support the theme. ${ }^{21}$

The transcripts were revisited to ensure the resulting themes reflected the patient's experiences. A second experienced qualitative researcher (JL) verified initial codes and subsequent analytical themes to ensure internal validity in relation to the data set. The resulting themes and supporting data were also reported and discussed at regular meetings of the research team as a process of member validation.

Anonymised verbatim quotes followed by the corresponding patient's study identification numbers are used throughout this section to illustrate key points. Patient demographics, employment details and time to return to work are reported to add additional context to the data (table 1). Return to work indicates the time taken to return to the place of work to either full or modified duties.

\section{RESULTS}

Three themes influencing the patient's experience of return to work following TKR were identified from the interview data. These were delays in surgical intervention and the impact on work participation preoperatively, limited and often inconsistent advice from healthcare professionals regarding return to work, and finally the absence of rehabilitation to optimise the individual's recovery and facilitate return to work.

\section{Theme 1: delays in surgical intervention}

The majority of patients perceived age to be a major barrier to referral for surgical intervention for knee OA. Patients described their frustrations at being told that they were too young to have a joint replacement despite the severity of symptoms and the subsequent impact on their quality of life. Patients described how they coped and adapted to prolonged periods of deteriorating physical function, limited mobility and instability, but for others, it was the physical and psychological impact of living with severe constant pain that was the dominant factor.

'There's nobody will replace your knee until you're 70'. That was the stock answer that I got from my GPs...I felt I was being fobbed off, at one stage it was looking like I was going to have to give up work altogether... I thought I was taking far too many painkillers to be able to function properly ...I was getting quite frustrated about it. ... you get depressed; I suppose is the right term for it, when you're in constant pain. [5]

'You're a little bit young to have it at the moment'. I thought, well, the type of job that I do is quite a strenuous job. I was having difficulty trying to climb the stepladders and things like that...because they (GPs) turned around and said, 'Well, you're better off if you can hang on until you're about 60 , because they don't do these operations unless it's essential that they do them'. [8]

\begin{tabular}{|c|c|c|c|c|c|c|}
\hline $\begin{array}{l}\text { Interview } \\
\text { number }\end{array}$ & $\begin{array}{l}\text { Gender } \\
\text { M/F }\end{array}$ & $\begin{array}{l}\text { Age at time of } \\
\text { surgery (years) }\end{array}$ & $\begin{array}{l}\text { Type of } \\
\text { employment }\end{array}$ & $\begin{array}{l}\text { Time taken to } \\
\text { RTW (weeks) }\end{array}$ & $\begin{array}{l}\text { Length of time after } \\
\text { surgery (months) }\end{array}$ & Sector \\
\hline 1 & $\mathrm{M}$ & 58 & IT & 12 & 9 & Private \\
\hline 2 & $\mathrm{~F}$ & 49 & $\begin{array}{l}\text { Supermarket } \\
\text { assistant }\end{array}$ & 13 & 21 & Private \\
\hline 3 & $\mathrm{~F}$ & 55 & GP receptionist & 12 & 14 & Public \\
\hline 4 & $M$ & 59 & Project engineer & $\begin{array}{l}6 \text { from home } \\
10 \text { at workplace }\end{array}$ & 21 & Private \\
\hline 5 & $M$ & 59 & $\begin{array}{l}\text { Self-employed } \\
\text { manager }\end{array}$ & 6 & 11 & Private \\
\hline 6 & $\mathrm{~F}$ & 57 & Teacher & 6 & 25 & Public \\
\hline 7 & $\mathrm{~F}$ & 47 & $\begin{array}{l}\text { Self-employed } \\
\text { farmer }\end{array}$ & 8 & 23 & Private \\
\hline 8 & M & 58 & Estates officer & 12 & 35 & Public \\
\hline 9 & $\mathrm{~F}$ & 40 & Administration & $\begin{array}{l}2 \text { from home } \\
5 \text { at workplace }\end{array}$ & 20 & Public \\
\hline 10 & M & 55 & HGV driver & 10 & 8 & Private \\
\hline
\end{tabular}


Absolutely refused to do it (NHS hospital). They said their policy wasn't to do it until they were 60 . Yes. I thought that was abysmal, especially since the knee was totally shot and I was getting a lot of pain with it. Quality of life had changed. [4]

As symptoms persisted and increased in severity, patients discussed the subsequent impact on work participation in terms of reduced productivity in the work place as well as patients reporting no choice but to take sick leave due to the inability to cope.

I would just go home and just be in tears with the pain... I eventually had to go on the sick because I just couldn't get through the day...I wasn't giving $100 \%$ to the job I should be doing cos I couldn't focus I just tended to focus just on the pain and getting through the day. [2]

Patients discussed the reasoning behind delaying surgery but were frustrated that their age was dictating their treatment options. Patients perceived that their individual circumstances and the need to remain in employment were not given due consideration in the decision-making process.

I can understand the argument that if you get them too early, they don't last too long and you might have to have them done again. I understand that, but you've got to trade that off with if it stops somebody working and then there are other effects to take into account, not just whether you're going to need it done again. [5]

Maybe I should have had it earlier when my muscles were in a better state, but I was getting to the state where I was barely moving and be very careful about how I was walking, where I was walking and the surface that I was walking on. I was only using stairs when I absolutely had to. That obviously makes your muscles a lot weaker. [9]

Patients reported the physical and psychological impact of delayed intervention as well as the resulting lost working days, financial implications, and the negative impact on their sickness record and future employability.

\section{Theme 2: limited and inconsistent advice between healthcare providers to optimise return to work}

Patients reported that the advice they received from healthcare professionals focused on the needs of the elderly, retired population. Preoperative education reportedly focused on the inpatient stay and immediate postoperative period, but longer term outcomes, such as return to work, were not routinely discussed.

[RTW] was not a big factor in any of the classes or any of the appointments I had about do you need help getting back to work... but I wouldn't say that's the fault of the whole process, it's just one of those things ...most of the patients I would of thought were beyond working age anyway or retired already ...that's the impression I get because of all the things that were mentioned, nothing about working so it gives you the impression that it's an older persons thing. [2]

There was no reference to work or no reference to what you could or couldn't do that I would be able to relate to...It was focused on people of a certain age and people who didn't work... It sounds silly to be asking those questions, but when nobody tells you anything, you think: 'Will I ever wear high heels again? ...When can I drive? ... Can I go to a low-impact fitness class, for example? Will I be able to kneel? When would I be able to have sex? [9]

Patients stated that the content of preoperative education they received reinforced the perception of joint replacement surgery as a procedure for the older retired population. Patients described themselves as the minority, and some reported that it was not appropriate to discuss issues pertinent to them, such as return to work, as it was not relevant to the majority of patients. As duration of absence due to sickness, and return to work, was not routinely discussed preoperatively, patients were unsure of the processes involved, and described looking to healthcare professionals postoperatively for guidance. Patients described waiting until their routine postoperative hospital review or GP appointment for the reassurance and guidance on when they were fit enough to resume activity or permission to return to work.

I have never been on the sick before I didn't know anything ...The only review I had (at 6 weeks post op) I was told that I should not consider going back until 13 weeks... I probably would have gone back after 6 weeks... Honestly I could have gone back but basically it was on her (Nurse Practitioner) advice. [1]

It was up to me when I went back to work, when I felt happy I went back... Invariably, I waited until the review which was anywhere between 10 and 12 weeks after the operation, although I'd been working from home, I waited until the review before I physically went back to work... [4]

It was the GP who said don't be rushing back ... she said 12 weeks... I could of gone back earlier ... to be quite honest I don't even know why I didn't go back ...I think it's the Dr said just don't rush back. [2]

Although most patients stated that it was they who made the decision when to return to work, they also described how this decision was influenced by the advice from healthcare professionals. The advice given at this time did not appear to be tailored to the individual but directly impacted patient's experience, on occasion delaying return to work even when patients felt able to return earlier. Some patients reportedly believed that they should not return to work until the clinician gives permission for insurance or health and safety reasons.

Just see what the consultant says first, whether you can go back...Because if they say no, really, you're not supposed 
to be back at work anyway because then you can't do your job or something happens, for health and safety, as well. So I based it on them saying, 'If you're fit enough to go back and you're well enough, that's it. Fine'. [3]

The majority of patients discussed the potential benefits of more tailored work-related advice, or the involvement of an occupational health worker to discuss the individual's requirements and facilitate the process of return to work. Those patients who did have occupational health involvement described their role in facilitating how they returned to work, but they did not advise on when to return.

They (Occupational health) just said keep in touch, let us know when you have had your operation and when you feel up to it well meet up and see how you are getting on and see how we can get you back to work ... I wanted to come back to work and I said that I couldn't do the job that I was doing before, she (occupational health) recommended that I went on to check outs the people person at the time said that's not a problem well get you back staggered (phased return). [2]

I think you've got to go down the occupational health type person who has some idea of people's work and what the work entails, as well as having a medical background someone capable of sitting down with an individual and discuss that individual's requirements and possibly a phased return to work, certainly on the physical aspects. [4]

\section{Theme 3: the provision of rehabilitation to optimise recovery and return to work}

Patients described a large variation in the provision of postoperative rehabilitation as well as reporting that the functional individual requirements needed for a safe effective return to work were not routinely considered. Rehabilitation goals were limited to general mobility and knee range of movement, and patients felt that they would have benefitted from more rehabilitation tailored to their individual needs.

I didn't get any (rehabilitation), just the booklet of what to do after a knee replacement from the trust, and the old exercises on the bed with a towel under your knee and things like that. I wish I had more professional physio'. More professional physio as opposed to do-it-yourself stuff at home. [5]

The physio was just the general physio that I had... (they) just want to see whether you'll get the target of 100 degrees or whatever it is. You've got to do the bend, you've got to do the flexion and then have a walk around. [4]

It was just basically trying to get the flexibility ... the bend back into the knee I think...you are only working solely on the knee... less of your physical fitness I mean if you're not moving around you're going to ... possibly lose a bit of ordinary fitness. [1]
I think the main thing was a little bit more physio aimed at what your needs were in terms of going back to work. For me, there would be a bit more knee-bending and stuff. It was more about walking, really, more than actually knee-bending. [7]

Although the rehabilitation they did receive was not tailored to their return to work requirements, patients reported that the interaction and feedback they did receive from rehabilitation staff gave them the reassurance and confidence to progress in their physical and psychological recovery.

It (Physiotherapy) was helpful because I was told by a professional that yes you are doing the right things and are you are progressing at the right rate and what is happening should be happening and I found that very helpful and encouraging. [2]

I don't know whether it is the physical act or whether it is just the idea that I am doing really well because somebody has told me that I am. I really don't know. I think it does build up your confidence, and that is the big factor for me to get me out there, make me feel a little bit better, and do what I am supposed to be doing. [9]

A small number of patients took the decision to seek additional rehabilitation, and reported the positive impact that the rehabilitation had on their physical function and ability to return to work.

I went and asked (workplace Human Resources) if it was possible to have physiotherapy. So I went to the rehab centre at (name of hospital), and I had about six weeks of that... I thought it would help me on, and make my legs stronger, which it did help me at the time... You feel like a new man type of thing after you've had loads and loads of exercise, and you're using muscles that you don't use... rehab is the thing I was very, very lucky to have. I would say myself it's the best thing to help you. [8]

My wife got us... a membership for the gym; I went to see them, 'I've had a knee replacement, I just need to get some exercises, build the strength up on the muscle above the knee.' They gave us a programme for that, I'm doing that. I'll be honest I think that's how I got back to work as quickly as I did. [10]

\section{DISCUSSION}

This qualitative study has explored the accounts and experiences of patients returning to work after TKR and identified three key factors influencing the patient's experience of return to work. Patients reported delays in surgical intervention and the subsequent impact on work participation preoperatively, limited and often inconsistent advice regarding return to work from healthcare professionals and, finally, the absence of rehabilitation to optimise individuals' recovery in relation to return to work requirements.

There are some limitations to this work. This was a single-site study representing a geographical area in the 
northeast of England. All patients were white British and under the age of 60 years at the time of surgery, therefore, the extent to which these findings relate to other regions and groups of patients is unknown at present. This study identifies factors influencing return to work following knee replacement, and patients not in employment prior to surgery were excluded from interview. The impact of OA on work participation and delayed intervention was identified in the study, but the experiences of patients forced out of work due to the impact of OA, or patients attempting to regain new employment following surgery were not addressed in this study. The retrospective nature of this study reports patients' experiences up to 36 months following surgery which will inevitably result in a risk of recall bias. Owing to the constraints of time, the number of interviews undertaken was limited to 10 , however, the aim of the study was not to reach data saturation but to identify important key themes. It is also worth highlighting that this study has presented the factors influencing return to work from the patient's perspectives, it does not report the perspectives of the healthcare professional or the employer but does identify their involvement in the process.

Patients in this study identified that the standard advice and treatment they received from their healthcare providers reinforced their perception that joint replacement is a surgery for the elderly, retired population. The increasing number of knee replacements performed in patients of working age has been well reported, and is projected to continue to rise exponentially. ${ }^{7}$ The findings of this study suggest that the increasing demand for TKR in the employed population has not been reflected in the patients' and clinicians' perceptions of the joint replacement patient, or in the subsequent provision of healthcare.

Patients described the severe impact of knee OA and pain on quality of life, and reported discrepancies between the patient and the GP's perception of the appropriate timing of surgical intervention. The findings of this study support those of previous work-pain intensity, impact on quality of life, and the ability to cope with pain which were considered the most important factors determining appropriateness for TKR by the patient cohort. This was considered to have been inadequately evaluated by the treating clinicians. ${ }^{25}{ }^{26}$ Criteria has been developed to determine the appropriateness for TKR based on pain, functional status and structural damage ${ }^{27-29}$ however, these guidelines have been found to be ambiguous, and previous literature has reported large variations in the GP's decision to refer for surgical opinion. ${ }^{26}{ }^{30-32}$ Previous studies have highlighted the correlation between lower preoperative function and episodes of sick leave, with more difficult rehabilitation and slower rates of return to work. ${ }^{12} 1519{ }^{33}$ Patients in this study wanted earlier referral for surgical intervention before they became debilitated by the physical and psychological impact of their OA. More timely intervention and consideration of the individual's functional requirements should reduce muscle wasting from $\mathrm{OA}$, and improve physical recovery. Benefits of both reduced preoperative sick leave and an earlier return to work following surgery will have social and economic benefits for patients, employers and society. ${ }^{3} 13$

Patients in this study identified a need for advice regarding work participation to be tailored to their individual employment needs. There is paucity of information in the literature to guide clinicians in advising patients regarding return to work following joint replacement. There are basic guidelines available in the grey literature such as the return to work guidance published by The Royal College of Surgeons, ${ }^{34}$ however, the extent to which such guidance is referred to is unknown.

Generic guidance is available regarding the use of the 'Fit note' introduced in 2010. ${ }^{35}$ Patients' experiences of the Fit note were not specifically included in the interview schedule, however, two of the 10 interview participants made reference to the 'fitness for work' or 'sick note' being extended over the phone, or being 'signed off'. Recent literature also suggests wide variation in its use for managing sick leave. ${ }^{36}$ The impact of advice and return to work interventions has not previously been reported in this group of patients. Previous work in other areas of surgery identified wide variations in the provision of advice to patients regarding absence due to sickness, ${ }^{37} 38$ and reported that the advice given by healthcare professionals appeared to have the greatest influence on return to work times, with patients tending to adhere to any advice that is given irrespective of its duration. Patients in this study were often advised to stay off work for longer than necessary with potential resultant costs to patients, employers and society. Consistent advice pertinent to the individual's employment could minimise the social and economic impact of time off work from TKR. Limited preoperative advice regarding return to work also means that patients may have unrealistic expectations. Patients with unclear expectations of their surgery will not be in a position to make a fully informed decision regarding whether or not to undergo knee replacement. Recent literature has highlighted the need for improved decision-making about the timing and indications for TKR, and the need to reduce variability in provision of surgery through education, training and the use of well-designed decision aids. ${ }^{5}{ }^{39}$ The advice and information we provide patients with is instrumental in allowing better decision-making.

Patients also described that rehabilitation was limited to the needs of the elderly retired population, and their requirements for return to work were not considered. A generic rehabilitation as described by patients in this study may not optimise a patient's ability to return to work. The concerns identified by patients in this study reflect findings of previous work. A systematic review of the effectiveness of physiotherapy exercise after knee replacement for $\mathrm{OA}^{40}$ reported that interventions to date have largely consisted of exercise programmes and 
gait rehabilitation, mainly targeting impairment and helping patients to recover from the effects of surgery rather than specifically targeting limitations in activity or restrictions in participation'. ${ }^{33}$ Return to work is not specifically discussed within the review, but it provided support for the use of physiotherapy exercise interventions with exercises based on functional activities rather than the traditional home exercise as described by patients in this study. Directed employment focused rehabilitation could potentially affect patients' physical ability to perform work-related tasks, but also to prepare them psychologically, giving them the reassurances and confidence needed to reduce anxiety surrounding reintegration back into the workforce.

\section{CONCLUSION}

Successful return to work is being increasingly recognised as an important outcome for this group of patients with social and economic implications for patients, employers and society. Recent studies have focused on predictors and rates of return to work rather than exploring why such factors influence the process of return to work.

This study has highlighted that there is currently no consistent process to optimise return to work for patients of working age after TKR. The impact of delayed surgical intervention, limited advice regarding return to work, and a lack of work-focused rehabilitation all contribute to potential delays in successful return to work. There is a need to change the focus of healthcare provision for this cohort of patients and provide a tailored healthcare intervention to optimise patient outcomes.

Improvements in delivery of these three aspects of patient care should be demonstrated by a high-quality interventional trial to determine the impact and efficacy on work participation following joint replacement. It is our hope that such an intervention will become integral to the service provided to this increasing cohort of patients.

Funding This research received no specific grant from any funding agency in the public, commercial or not-for-profit sectors.

Competing interests None declared.

Ethics approval Local R\&D approval was obtained (R\&D ref: 6525) and ethical approvals were granted by the Proportionate Review Sub-committee of the NRES Committee London (REC ID: 13/LO/0719).

Provenance and peer review Not commissioned; externally peer reviewed.

Data sharing statement No additional data are available.

Open Access This is an Open Access article distributed in accordance with the Creative Commons Attribution Non Commercial (CC BY-NC 4.0) license, which permits others to distribute, remix, adapt, build upon this work noncommercially, and license their derivative works on different terms, provided the original work is properly cited and the use is non-commercial. See: http:// creativecommons.org/licenses/by-nc/4.0/

\section{REFERENCES}

1. Palmer KT. The older worker with osteoarthritis of the knee. Br Med Bull 2012;102:79-88.
2. Hubertsson J, Petersson IF, Thorstensson CA, et al. Risk of sick leave and disability pension in working-age women and men with knee osteoarthritis. Ann Rheum Dis 2013;72:401-5.

3. Li X, Gignac MA, Anis AH. The indirect costs of arthritis resulting from unemployment, reduced performance, and occupational changes while at work. Med Care 2006;44:304-10.

4. Liang MH, Cullen KE, Larson MG, et al. Cost-effectiveness of total joint arthroplasty in osteoarthritis. Arthritis Rheum 1986;29:937-43.

5. Kievit AJ, Van Geenen RC, Kuijer PPFM, et al. Total knee arthroplasty and the unforeseen impact on return to work: a cross-sectional multicenter survey. J Arthroplasty 2014;29:1163-8.

6. Anderson R, Thomas DW. 'Toothache stories': a qualitative investigation of why and how people seek emergency dental care. Community Dent Health 2003;20:106-11.

7. Kurtz SM, Lau E, Ong K, et al. Future young patient demand for primary and revision joint replacement: national projections from 2010 to 2030. Clin Orthop Relat Res 2009;467:2606-12.

8. Ruiz D Jr, Koenig L, Dall TM, et al. The direct and indirect costs to society of treatment for end-stage knee osteoarthritis. J Bone Joint Surg Am 2013;95:1473-80.

9. Waddell GP. Is work good for your health? [Miscellaneous]. J Bone Joint Surg Br 2008;2008:487-8.

10. Lombardi AV Jr, Nunley RM, Berend KR, et al. Do patients return to work after total knee arthroplasty? Clin Orthop Relat Res 2014;472:138-46.

11. Foote JAJ, Smith HK, Jonas SC, et al. Return to work following knee arthroplasty. Knee 2010;17:19-22.

12. Styron JF, Barsoum WK, Smyth KA, et al. Preoperative predictors of returning to work following primary total knee arthroplasty. J Bone Joint Surg Am 2011;93:2-10.

13. Tilbury C, Schaasberg W, Plevier JW, et al. Return to work after total hip and knee arthroplasty: a systematic review. Rheumatology (Oxford) 2014;53:512-25.

14. Sankar A, Davis AM, Palaganas MP, et al. Return to work and workplace activity limitations following total hip or knee replacement. Osteoarthr Cartil 2013;21:1485-93.

15. Bohm ER. The effect of total hip arthroplasty on employment. J Arthroplasty 2010;25:15-18.

16. Barrack RL Ruh EL, Chen J, et al. Impact of socioeconomic factors on outcome of total knee arthroplasty. Clin Orthop Relat Res 2014;472:86-97.

17. Malviya A, Wilson $\mathrm{G}$, Kleim B, et al. Factors influencing return to work after hip and knee replacement. Occup Med (Oxford) 2014;64:402-9.

18. Pope C, Mays N, eds. Qualitative research in health care. Blackwell, 2006.

19. Kleim BD, Malviya A, Rushton S, et al. Understanding the patient reported factors determining time taken to return to work after hip and knee arthroplasty. Knee Surg Sports Traumatol Arthrosc 2015;23:3646-52.

20. Braun V, Clarke V. Using thematic analysis in psychology. Qual Res Psychol 2006;3:77-101.

21. Braun V, Clarke V, Terry G. Thematic analysis. In: Rohleder $P$, Lyons AC, eds. Qualitaive research in clincial health psychology. New York: Palgrave Macmillan, 2015:95-113.

22. Robb KA, Simon AE, Miles A, et al. Public perceptions of cancer: a qualitative study of the balance of positive and negative beliefs. BMJ Open 2014;4:e005434.

23. Low EL, Whitaker KL, Simon AE, et al. Women's interpretation of and responses to potential gynaecological cancer symptoms: a qualitative interview study. BMJ Open 2015;5:e008082.

24. Daly J, Kellehear A, Gliksman M. The public health researcher: a methodological approach. Melbourne, Australia: Oxford University Press, 1997.

25. Frankel L, Sanmartin C, Conner-Spady B, et al. Osteoarthritis patients' perceptions of "appropriateness" for total joint replacement surgery. Osteoarthr Cartil 2012;20:967-73.

26. McHugh GA, Campbell M, Luker KA. GP referral of patients with osteoarthritis for consideration of total joint replacement: a longitudinal study. Br J Gen Pract 2011; 61:e459-68.

27. Rankin EA, Alarcon GS, Chang RW, et al. NIH consensus statement on total knee replacement December 8-10, 2003. J Bone Joint Surg Am 2004;86:1328-35.

28. Naylor CD, Williams JI. Primary hip and knee replacement surgery: Ontario criteria for case selection and surgical priority. Qual Health Care 1996;5:20-30.

29. Rhon D. Re: Zhang W, Moskowitz RW, Nuki G, et al. OARSI recommendations for the management of hip and knee 
osteoarthritis, Part II: OARSI evidence-based, expert consensus guidelines. Osteoarthritis Cartilage 2008;16:137-62. Osteoarthr Cartil 2008;16:1585; author reply 9.

30. Hawker GA, Badley EM, Borkhoff CM, et al. Which patients are most likely to benefit from total joint arthroplasty? Arthritis Rheum 2013;65:1243-52.

31. Hudak PL, Grassau P, Glazier RH, et al. "Not everyone who needs one is going to get one": The influence of medical brokering on patient candidacy for total joint arthroplasty. Med Decis Making 2008;28:773-80.

32. Ringberg $\mathrm{U}$, Fleten $\mathrm{N}$, Frode $\mathrm{OH}$. Examining the variation in GPs' referral practice: a cross-sectional study of GPs' reasons for referral. Br J Gen Pract 2014;64:e426-33.

33. Jorn LP, Johnsson R, Toksvig-Larsen S. Patient satisfaction, function and return to work after knee arthroplasty. Acta Orthop Scand 1999;70:343-7.

34. Goldstein GR, Preston JD. Therapy: anecdote, experience, or evidence? Dent Clin North Am 2002;46:21-8.
35. Getting the most out of the fit note. https://www.gov.uk/government/ uploads/system/uploads/attachment data/file/447605/ fit-note-gps-guidance-jan-15.pdf: Gov.co.uk; [cited 2015].

36. O'Dowd A. Lack of information on "fit notes" renders them useless, says study. BMJ 2015;351:h4214.

37. Clayton M, Verow P. Advice given to patients about return to work and driving following surgery. Occup Med (Oxford) 2007:57:488-91.

38. Dasinger LK, Krause N, Thompson PJ, et al. Doctor proactive communication, return-to-work recommendation, and duration of disability after a workers' compensation low back injury. J Occup Environ Med 2001;43:515-25.

39. Carr AJ, Robertsson O, Graves S, et al. Knee replacement. Lancet 2012;379:1331-40.

40. Minns Lowe CJ, Barker KL, Dewey M, et al. Effectiveness of physiotherapy exercise after knee arthroplasty for osteoarthritis: systematic review and meta-analysis of randomised controlled trials. BMJ 2007;335:812. 